\title{
Differential Effects of Endotracheal Suctioning on Gas Exchanges in Patients with Acute Respiratory Failure under Pressure-Controlled and Volume-Controlled Ventilation
}

\author{
Xiao-Wei Liu, ${ }^{1}$ Yan Jin, ${ }^{1}$ Tao Ma, ${ }^{1}$ Bo Qu, ${ }^{2}$ and Zhi Liu ${ }^{1}$ \\ ${ }^{1}$ Department of Emergency, The First Affiliated Hospital of China Medical University, Shenyang 110001, China \\ ${ }^{2}$ Department of Biostatistics, School of Public Health, China Medical University, Shenyang 110001, China
}

Correspondence should be addressed to Zhi Liu; cmulh_lz@163.com

Received 19 June 2014; Revised 5 February 2015; Accepted 23 March 2015

Academic Editor: Yumiko Imai

Copyright (C) 2015 Xiao-Wei Liu et al. This is an open access article distributed under the Creative Commons Attribution License, which permits unrestricted use, distribution, and reproduction in any medium, provided the original work is properly cited.

\begin{abstract}
This study was conducted to evaluate the effects of open endotracheal suctioning on gas exchange and respiratory mechanics in ARF patients under the modes of PCV or VCV. Ninety-six ARF patients were treated with open endotracheal suctioning and their variations in respiratory mechanics and gas exchange after the suctions were compared. Under PCV mode, compared with the initial level of tidal volume $\left(V_{T}\right)$, ARF patients showed $30.0 \%$ and $27.8 \%$ decrease at $1 \mathrm{~min}$ and $10 \mathrm{~min}$, respectively. Furthermore, the initial respiratory system compliance $\left(C_{\mathrm{rs}}\right)$ decreased by $29.6 \%$ and $28.5 \%$ at $1 \mathrm{~min}$ and $10 \mathrm{~min}$, respectively. Under VCV mode, compared with the initial level, $38.6 \%$ and $37.5 \%$ increase in peak airway pressure (PAP) were found at 1 min and 10 min, respectively. Under PCV mode, the initial $\mathrm{PaO}_{2}$ increased by $6.4 \%$ and $10.2 \%$ at $3 \mathrm{~min}$ and $10 \mathrm{~min}$, respectively, while $18.9 \%$ and $30.6 \%$ increase of the initial $\mathrm{PaO}_{2}$ were observed under VCV mode. Summarily, endotracheal suctioning may impair gas exchange and decrease lung compliance in ARF patients receiving mechanical ventilation under both PCV and VCV modes, but endotracheal suctioning effects on gas exchange were more severe and longer-lasting under PCV mode than VCV.
\end{abstract}

\section{Introduction}

Respiratory failure is an acute or chronic condition with impaired gas exchange and pulmonary functions and is characterized by elevated carbon dioxide or decreased oxygen in the arterial blood [1]. Respiratory failure can result from diverse conditions such as cardiac and respiratory diseases, defects in neuromuscular systems that control breathing, injury to chest, and several lung diseases. Importantly, respiratory failure is associated with a high morbidity and mortality $[2,3]$. The majority of patients with respiratory failure exhibit shortness of breath, and the low oxygen and high carbon dioxide levels in the blood can impair heart and brain functions $[4,5]$. Currently, treatment for respiratory failure includes clearing the airways by suction, use of bronchodilators, or tracheostomy and endotracheal tube with ventilator support. Additionally, the treatment regimen includes antibiotics for infections, anticoagulants for pulmonary thromboembolism, and electrolyte replacement for fluid imbalance [4]. Mechanical ventilation is a method to mechanically assist or replace spontaneous breathing to cure respiratory failure [6]. Mechanical ventilation is effective in improving gas exchange, while reducing dyspnea and inspiratory effort in patients with respiratory failure, and averts risks secondary to endotracheal intubation $[7,8]$.

Due to establishment of artificial airway, most acute respiratory failure (ARF) patients receiving mechanical ventilation could not produce sputum. Suctioning could effectively eliminate airway secretions to maintain respiratory function [9]. Endotracheal suctioning is required to avert accumulation of secretions and its related complications and to maintain airway patency [10]. During open endotracheal suctioning, gas aspirated from the lung will facilitate the movement of secretions towards the suction catheter [11]. However, ARF patients are separated from the ventilator during open endotracheal suctioning, which may decrease positive airway pressure (PAP) and lung volume [4]. Alveolar collapse may induce a further decline in lung volume during negative-pressure suction [12], thereby affecting gas exchange and respiratory mechanics in ARF patients [2]. This study 
TABLE 1: Comparison of patients' general information between the two groups.

\begin{tabular}{lccrr}
\hline General information & PCV (49) & VCV (47) & $t / F$ & 0.379 \\
\hline Gender (M/F) & $25 / 24$ & $20 / 27$ & 0.207 & 0.538 \\
Age & $57 \pm 21.1$ & $58 \pm 26.2$ & 0.192 & 0.836 \\
APACHE II & $17.6 \pm 10.3$ & $17.2 \pm 10.1$ & 1.165 & 0.848 \\
Disease course & $4.6 \pm 2.0$ & $5.1 \pm 2.2$ & 1.124 & 0.247 \\
Complications & 15 & 20 & 0.289 \\
\hline
\end{tabular}

M: male; F: female; APACHE: acute physiology and chronic health evaluation.

investigated the effects of open endotracheal suctioning on respiratory mechanics and gas exchange in ARF patients under PCV and VCV.

\section{Methods}

2.1. Ethics Statement. The Ethics Committee of the First Affiliated Hospital of China Medical University approved this study. Written informed consent was acquired from all subjects using the procedures authorized by institutional review boards. Next of kin, caretakers, or guardians consented representing the study participants whose capacity to consent was reduced. The study was executed at the emergency intensive care units (EICU) at the First Affiliated Hospital of China Medical University.

2.2. Study Design and Subjects. This was a single center prospective study of acute respiratory failure (ARF) patients admitted to the EICU between October 2010 and February 2013. Patients met the following criteria to be enrolled in this study; patients lived up to the criteria for the diagnosis of ARF: (1) type I: $\mathrm{PaO}_{2}<60 \mathrm{mmHg}, \mathrm{PaCO}_{2}<50 \mathrm{mmHg}$; (2) type II: $\mathrm{PaO}_{2}<60 \mathrm{mmHg}, \mathrm{PaCO}_{2} \geq 50 \mathrm{mmHg}$. All patients received endotracheal intubation and continuous mechanical ventilation (Maquet, Servo V.2.0, Germany), continuous monitoring of heart rate (HR), blood pressure (BP), and $\mathrm{SpO}_{2}$ with Philips Intellivue MP60 monitor (Philips, Medizinsysteme, Germany).

In the present study, ninety-six acute respiratory failure (ARF) patients (45 males and 51 females) were enrolled, with a mean age of 62 years (range: 26 84 years). They were divided into two groups: PCV and VCV. PCV group included 49 patients (25 males and 24 females), with a mean age of $(57 \pm 21)$ years. And they were with an APACHE II score of (17.6 \pm 10.3$)$, a disease course of ( $4.6 \pm$ 2.0) years. There were 15 patients who had complications, such as compensatory chronic respiratory failure, acidosis, pulmonary encephalopathy, and gastrointestinal bleeding. Compared with PCV, VCV group had 47 patients (20 males and 27 females), with a mean age of $(58 \pm 26)$ years. Their APACHE II score was $(17.2 \pm 10.1)$ and disease course was $(5.1 \pm 2.2)$ years. Twenty among them had complications, including compensatory chronic respiratory failure, acidosis, pulmonary encephalopathy, and gastrointestinal bleeding. As shown in Table 1, there was no statistical difference in gender ratio, age, APACHE II score, disease course, and complications between the two groups of subjects (all $P>$ $0.05)$.
2.3. Protocol. The 96 ARF patients were randomly divided into the PCV and VCV groups using a random number generator. Diazepam (10 mg) was injected intravenously before suctioning. A standardized method was used for a standardized lung volume method after $1 \mathrm{~h}$ of mechanical ventilation: (1) sufficient suctioning for mouth, nasal, and airway secretions; (2) $10 \mathrm{~cm} \mathrm{H}_{2} \mathrm{O}(0.98 \mathrm{kPa})$ plateau airway pressure $\left(P_{\text {plat }}\right)$ by increasing tidal volume $\left(V_{T}\right)$ under VCV mode and $10 \mathrm{~cm} \mathrm{H}_{2} \mathrm{O}$ inspiratory pressure under PCV mode, maintaining ventilation and oxygenation for 20 s. According to the clinical need for suctioning, suction indications include visible secretions attached within the patient's endotracheal tube, auscultation of lung breath weak sound and sputum sound, patients with irritability and other poor performances, changes, or abnormities in breathing rate, slowness of heart rate, increase in blood pressure, reduction of ventilation, and detection of $\mathrm{SpO}_{2}$ less than 90\%. Endotracheal suctioning was performed when alarm for peak airway pressure $\left(P_{\text {peak }}\right)$ under VCV mode, low tidal volume under $\mathrm{PCV}$, or $\mathrm{SpO}_{2}$ decreased more than 5\%. During endotracheal suctioning, endotracheal tube departed from Y-shaped tube. The $12 \mathrm{~F}$ suction catheter ( $4 \mathrm{~mm}$ exterior diameter) was inserted into endotracheal tube about $30 \mathrm{~cm}$ after blocking negative pressure suction and then slowly rotated and the suction catheter was withdrawn at $150 \mathrm{mmHg}$. Endotracheal tube was connected with ventilator tube for mechanical ventilation after suctioning.

2.4. Outcome Measurements. The HR, mean arterial pressure (MAP), $V_{T}, P_{\text {peak }}$, and $P_{\text {plat }}$ were recorded at $15 \mathrm{~min}$ after standardized lung volume (baseline), before suctioning, and $1,3,5$, and $10 \mathrm{~min}$ after suctioning. Total respiratory system compliance $\left(C_{\mathrm{rs}}\right)$ was reckoned by $\left[C_{\mathrm{rs}}=V_{T} /\left(P_{\text {peak }}-\right.\right.$ $\left.\left.\operatorname{PEEP}\left(5-8 \mathrm{~cm} \mathrm{H}_{2} \mathrm{O}\right)\right)\right]$. Values of $V_{T}, P_{\text {peak }}$, and $P_{\text {plat }}$ were the average of five respiratory cycles. Dynamic changes in $\mathrm{SpO}_{2}$ were monitored. Arterial blood gas analysis was performed at baseline, before suctioning, and at 3 and $10 \mathrm{~min}$ after suctioning.

2.5. Statistical Analysis. Data was presented as mean \pm standard deviation (SD), median with interquartile ranges (IQR), or frequencies. A $\chi^{2}$ test was used to compare frequencies. One-way analysis of variance (ANOVA) and Student's $t$-test were applied to generally distributed variables, while the Mann-Whitney $U$ test was applied to nonnormal distributed variables. Comparisons between two groups for nominal variables were made by the Fisher exact test. All of the statistical significance tests were two-sided, with a $P$ value 
TABLE 2: Changes in heart rate (HR) and mean arterial pressure (MAP) before and after suctioning at different time points under PCV and VCV modes.

\begin{tabular}{lcccc}
\hline Time & & & & VCV \\
& HR (beat/min) & MAP (mmHg) & HR (beat/min) & MAP (mmHg) \\
\hline Basic level & $95 \pm 13$ & $82 \pm 12$ & $96 \pm 17$ & $81 \pm 10$ \\
Before suctioning & $117 \pm 16$ & $86 \pm 13$ & $112 \pm 15$ & $86 \pm 14$ \\
1 min & $122 \pm 17^{*}$ & $89 \pm 15^{*}$ & $109 \pm 12^{*}$ & $88 \pm 16^{*}$ \\
3 min & $108 \pm 15^{*}$ & $90 \pm 17^{*}$ & $104 \pm 12^{*}$ & $89 \pm 12^{*}$ \\
5 min & $105 \pm 17^{*}$ & $91 \pm 14^{*}$ & $106 \pm 21^{*}$ & $90 \pm 12^{*}$ \\
10 min & $100 \pm 14$ & $87 \pm 13$ & $98 \pm 17$ & $84 \pm 14$ \\
\hline
\end{tabular}

${ }^{*}$ Compared with the baseline, $P<0.05$; HR: heart rate; MAP: mean arterial pressure; PCV: pressure-controlled ventilation; VCV: volume-controlled ventilation.

less than 0.05 considered as statistically significant. All the statistical analysis was performed by the use of SPSS 18.0 software (SPSS, Inc., Chicago, IL, USA).

\section{Results}

3.1. Changes in Hemodynamic Parameters. Changes in heart rate (HR) and mean arterial pressure (MAP) before and after suctioning at different time points under PCV and VCV modes are shown in Table 2. Under PCV mode, the HR and MAP showed an increase of $10.5 \%$ and $11 \%$, respectively, at 5 min after suctioning, compared with the baseline level (HR: $105 \pm 17$ versus $95 \pm 13$ minute $^{-1}, P<0.05$; MAP: $91 \pm 14$ versus $82 \pm 12 \mathrm{mmHg}, P<0.05$, resp.). Under VCV mode, the HR and MAP increased by $10.4 \%$ and $11.1 \%$, respectively, at $5 \mathrm{~min}$ after suctioning compared with the baseline level (HR: $106 \pm 21$ versus $96 \pm 17$ minute $^{-1}, P<0.05$; MAP: $90 \pm 12$ versus $81 \pm 10 \mathrm{mmHg}, P<0.05$, resp.). No significant differences were found in changes in HR and MAP at $10 \mathrm{~min}$ after suctioning compared with the baseline level under both PCV and VCV modes (all $P>0.05$ ). Furthermore, there were also no significant differences in HR and MAP between PCV and VCV modes at different time points after suctioning (all $P>0.05)$.

3.2. Changes in Respiratory Mechanics. Changes in tidal volume $\left(V_{T}\right), C_{\mathrm{rs}}$, and airway pressure in ARF patients before and after suctioning at different time points are shown in Table 3. Under PCV mode, the $V_{T}$ and $C_{\mathrm{rs}}$ showed a decrease of $30.0 \%$ and $29.6 \%$, respectively, at $1 \mathrm{~min}$ after suctioning, compared with the baseline level $\left(V_{T}: 6.3 \pm 1.8\right.$ versus $9.0 \pm 0.1 \mathrm{~mL} / \mathrm{kg}$, $P<0.05 ; C_{\mathrm{rs}}: 17.8 \pm 6.8$ versus $25.3 \pm 7.8 \mathrm{~mL} / \mathrm{cm} \mathrm{H}_{2} \mathrm{O}$, $P<0.05$, resp.) (Figures 1-2). At $10 \mathrm{~min}$ after suction, the $V_{T}$ and $C_{\mathrm{rs}}$ decreased by $27.8 \%$ and $28.5 \%$, respectively $\left(V_{T}\right.$ : $6.5 \pm 2.0$ versus $9.0 \pm 0.1 \mathrm{~mL} / \mathrm{kg}, P<0.05 ; C_{\mathrm{rs}}: 18.1 \pm 7.3$ versus $25.3 \pm 7.8 \mathrm{~mL} / \mathrm{cm} \mathrm{H}_{2} \mathrm{O}, P<0.05$, resp.). No significant differences were found for changes in the $V_{T}$ and $C_{\mathrm{rs}}$ at $10 \mathrm{~min}$ after suctioning, compared with baseline level (all $P>0.05$ ).

Under VCV mode, peak airway pressure $\left(P_{\text {peak }}\right)$ and plateau pressure $\left(P_{\text {plat }}\right)$ showed an increase of $38.6 \%$ and $17.2 \%$, respectively, at $1 \mathrm{~min}$ after suctioning, compared with the baseline level $\left(P_{\text {peak }}: 34.8 \pm 8.4\right.$ versus $25.1 \pm 7.5 \mathrm{~cm} \mathrm{H}_{2} \mathrm{O}$, $P<0.05 ; P_{\text {plat }}: 27.9 \pm 7.3$ versus $23.8 \pm 5.8 \mathrm{~cm} \mathrm{H}_{2} \mathrm{O}, P<0.05$, resp.), while $C_{\mathrm{rs}}$ decreased by $32.5 \%$ (16.6 \pm 5.1 versus $24.6 \pm$

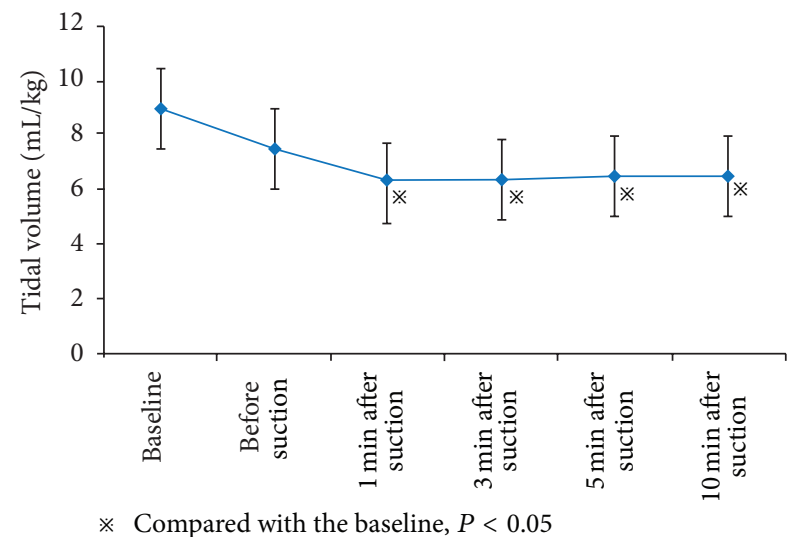

FIGURE 1: Changes in tidal volume $\left(V_{T}\right)$ under PCV mode of ARF patients before and after suctioning at different time points.

$6.3 \mathrm{~mL} / \mathrm{cm} \mathrm{H}_{2} \mathrm{O}, P<0.05$ ) (Figures 2-3). At $10 \mathrm{~min}$ after suctioning, the $P_{\text {peak }}$ and $P_{\text {plat }}$ showed an increase of $37.5 \%$ and $17.6 \%$, respectively $\left(P_{\text {peak }}: 34.5 \pm 8.2\right.$ versus $25.1 \pm 7.5 \mathrm{~cm} \mathrm{H}_{2} \mathrm{O}$, $P<0.05$; $P_{\text {plat }}: 28.0 \pm 7.6$ versus $23.8 \pm 5.8 \mathrm{~cm} \mathrm{H}_{2} \mathrm{O}, P<$ 0.05 , resp.), while $C_{\mathrm{rs}}$ decreased by $31.7 \%$ (16.8 \pm 5.5 versus $24.6 \pm 6.3 \mathrm{~mL} / \mathrm{cm} \mathrm{H}_{2} \mathrm{O}, P<0.05$ ). Compared with the level before suction, $t$ changes in the $P_{\text {peak }}$ and $C_{\mathrm{rs}}$ at $10 \mathrm{~min}$ after suctioning also did not represent notable differences (all $P>$ 0.05).

3.3. Changes in Gas Exchange. Under PCV mode, compared with the initial level before suctioning, $\mathrm{PaO}_{2}$ showed an increase of $6.4 \%$ and $10.2 \%$ at 3 and $10 \mathrm{~min}$, respectively, after suctioning ( $3 \mathrm{~min}$ : $67.7 \pm 13.2 \mathrm{mmHg}$ versus $63.6 \pm$ $14.1 \mathrm{mmHg}, P>0.05$; $10 \mathrm{~min}: 70.1 \pm 18.7 \mathrm{mmHg}$ versus $63.6 \pm 14.1 \mathrm{mmHg}, P>0.05$, resp.) (Figure 4). However, there was still a prominent difference in $\mathrm{PaO}_{2}$ between the baseline level and the level at $10 \mathrm{~min}$ after suctioning (70.1 \pm $18.7 \mathrm{mmHg}$ versus $89.6 \pm 15.1 \mathrm{mmHg}, P<0.05)$. Under VCV mode, compared with the level before suction, $\mathrm{PaO}_{2}$ also showed an increase of $18.9 \%$ and $30.6 \%$ at 3 and $10 \mathrm{~min}$, respectively, after suctioning ( $3 \mathrm{~min}: 76.2 \pm 13.6 \mathrm{mmHg}$ versus $64.1 \pm 13.2 \mathrm{mmHg}, P<0.05 ; 10 \mathrm{~min}: 83.7 \pm 16.9 \mathrm{mmHg}$ versus $64.1 \pm 13.2 \mathrm{mmHg}, P<0.05$, resp.). There was no obvious difference in $\mathrm{PaO}_{2}$ between the baseline level and the level at $10 \mathrm{~min}$ after suctioning $(83.7 \pm 16.9 \mathrm{mmHg}$ versus $85.1 \pm$ 
TABLE 3: Tidal volume $\left(V_{T}\right)$, respiratory system compliance $\left(C_{\mathrm{rs}}\right)$, and airway pressure changes before and after endotracheal suctioning under pressure-controlled ventilation (PCV) or volume-controlled ventilation (VCV).

\begin{tabular}{|c|c|c|c|c|c|}
\hline \multirow{2}{*}{ Time } & \multicolumn{2}{|c|}{ PCV } & \multicolumn{3}{|c|}{ VCV } \\
\hline & $V_{T}(\mathrm{~mL} / \mathrm{kg})$ & $\begin{array}{c}C_{\mathrm{rs}} \\
\left(\mathrm{mL} / \mathrm{cmH}_{2} \mathrm{O}\right)\end{array}$ & $P_{\text {peak }}\left(\mathrm{cmH}_{2} \mathrm{O}\right)$ & $C_{\mathrm{rs}}\left(\mathrm{mL} / \mathrm{cmH}_{2} \mathrm{O}\right)$ & $P_{\text {plat }}\left(\mathrm{cmH}_{2} \mathrm{O}\right)$ \\
\hline Baseline level & $9.0 \pm 0.1$ & $25.3 \pm 7.8$ & $25.1 \pm 7.5$ & $24.6 \pm 6.3$ & $23.8 \pm 5.8$ \\
\hline Before suctioning & $7.5 \pm 2.2^{*}$ & $20.9 \pm 5.8^{*}$ & $36.2 \pm 8.7^{*}$ & $15.9 \pm 5.8^{*}$ & $26.2 \pm 6.4$ \\
\hline $1 \mathrm{~min}$ & $6.3 \pm 1.8^{*}$ & $17.8 \pm 6.8^{*}$ & $34.8 \pm 8.4^{*}$ & $16.6 \pm 5.1^{*}$ & $27.9 \pm 7.3^{*}$ \\
\hline $3 \mathrm{~min}$ & $6.4 \pm 1.9^{*}$ & $17.8 \pm 6.3^{*}$ & $34.9 \pm 6.5^{*}$ & $16.6 \pm 6.6^{*}$ & $27.8 \pm 5.9^{*}$ \\
\hline $5 \mathrm{~min}$ & $6.5 \pm 1.6^{*}$ & $18.0 \pm 6.7^{*}$ & $34.7 \pm 7.8^{*}$ & $16.7 \pm 6.4^{*}$ & $27.9 \pm 6.9^{*}$ \\
\hline $10 \mathrm{~min}$ & $6.5 \pm 2.0^{*}$ & $18.1 \pm 7.3^{*}$ & $34.5 \pm 8.2^{*}$ & $16.8 \pm 5.5^{*}$ & $28.0 \pm 7.6^{*}$ \\
\hline
\end{tabular}

${ }^{*} P<0.05$, compared with the baseline level, PCV: pressure-controlled ventilation, VCV: volume-controlled ventilation, $V_{T}$ : tidal volume, $P_{\text {peak }}$ : airway peak pressure, $C_{\mathrm{rs}}$ : respiratory system compliance, and $P_{\text {plat }}$ : airway plat pressure.

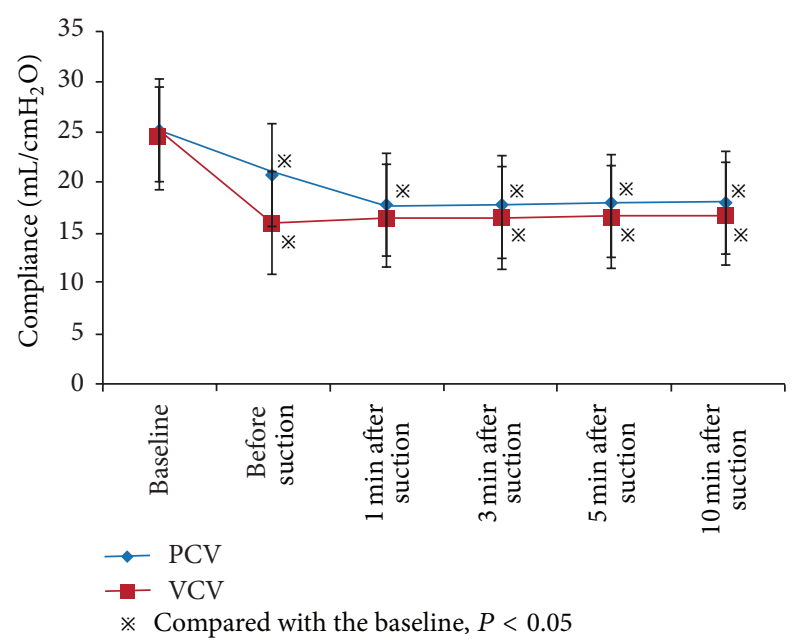

FIGURE 2: Changes in respiratory system compliance $\left(C_{\mathrm{rs}}\right)$ of ARF patients before and after suctioning at different time points under PCV and VCV modes.

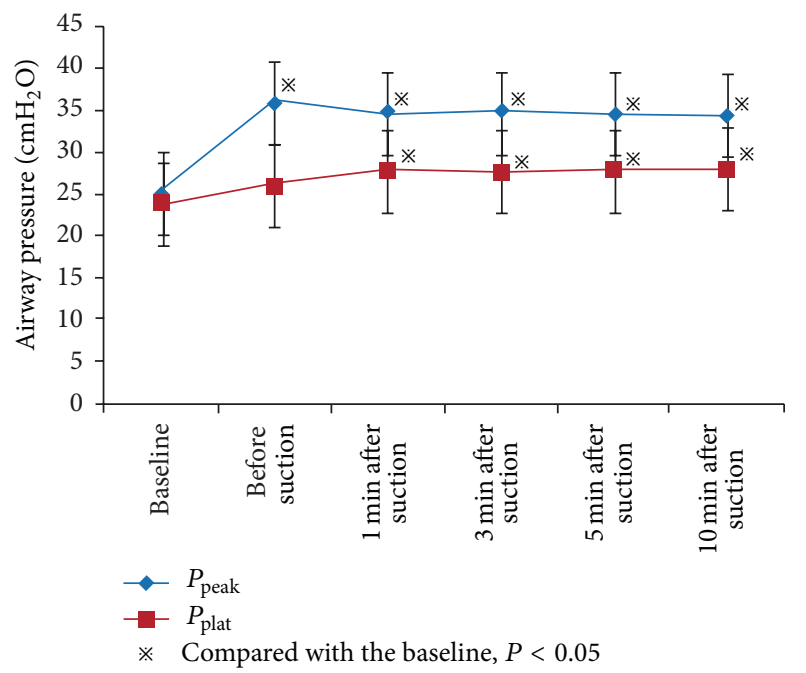

FIGURE 3: Changes in airway pressure of ARF patients before and after suctioning at different time points under VCV mode.

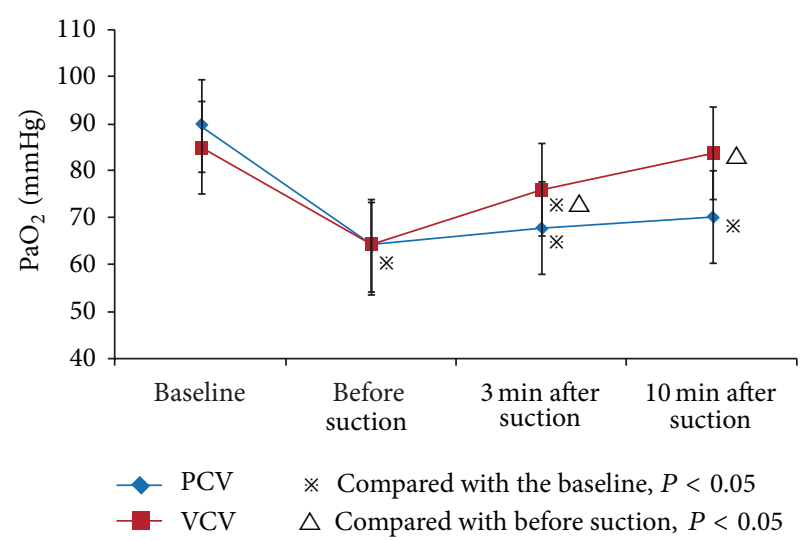

FIgure 4: Changes in $\mathrm{PaO}_{2}$ of ARF patients before and after suctioning at different time points under PCV and VCV modes.

$14.2 \mathrm{mmHg}, P>0.05)$. We have demonstrated that under PCV mode $\mathrm{PaO}_{2}$ had a mean increase $(3 \mathrm{~min}:(6.4 \pm 2.6)$ $\%$; $10 \mathrm{~min}$ : (10.2 \pm 6.2$) \%)$ for ARF patients after suctioning compared with before suctioning, and the increased ratio was lower than under VCV mode (all $P<0.05$ ).

\section{Discussion}

Mechanical ventilation mechanically assists or replaces spontaneous breathing [13]. In general, mechanical ventilation should be considered when there are clinical or laboratory signs that the patient cannot maintain an open airway or adequate oxygenation or ventilation [14]. Endotracheal suctioning is a frequently performed procedure for acute respiratory failure patients receiving mechanical ventilation [15]. Endotracheal suctioning can avoid accumulation of secretions, tracheal occlusion, increased work of breathing, atelectasis, and pulmonary infections, thereby ensuring optimal oxygenation or ventilation [16]. However, endotracheal suctioning may also cause opposite effects, such as arrhythmia, hypoxemia, airway and environment microbial contamination, and ventilator-associated pneumonia (VAP) [16]. Furthermore, endotracheal suctioning may lead to different effects on gas exchange and respiratory mechanics in 
acute respiratory failure patients under the mode of volumecontrolled ventilation (VCV) and pressure-controlled ventilation $(\mathrm{PCV})$. Open suctioning requires the ventilator to be disconnected and many patients experience anxiety and fear during suction, which results in resentment and irritability and potential psychological stress disorders. The closed circuit suctioning maintains the connection with the ventilator, giving patients the required sense of security. By the comparison of the open suctioning and closed circuit suctioning methods, these evidences supported that closed circuit suctioning is superior to open suctioning [17]. Under VCV mode, increase of airway pressure was in response to reduced compliance, increased resistance, or active exhalation and may increase ventilator-induced lung injury risk. PCV inhibits most of airway pressure delivered to the lung but may lead to changeable tidal and minute volume [18]. However, there are few studies on differential effects of endotracheal suctioning in acute respiratory failure patients under PCV and VCV.

In the present study, we evaluated endotracheal suctioning effects on gas exchange and respiratory mechanics in 96 ARF patients under PCV and VCV modes. Our results indicated that endotracheal suctioning under PCV and VCV modes impairs both gas exchange and respiratory mechanics in ARF patients receiving mechanical ventilation. Compared with the initial level of $V_{T}$, ARF patients showed a $30.0 \%$ and $27.8 \%$ decrease at $1 \mathrm{~min}$ and $10 \mathrm{~min}$, respectively, after suctions under PCV mode. Alveolar collapse under PCV mode could lead to an increased respiratory resistance when the inspiratory pressure was stabilized on a fixed point, thereby causing $V_{T}$ to reduce [19]. Furthermore, the initial $C_{\text {rs }}$ decreased by $29.6 \%$ and $28.5 \%$ at $1 \mathrm{~min}$ and $10 \mathrm{~min}$, respectively, after suctions under PCV mode. The major causes of suctioning effects on respiratory mechanics include alveolar collapse, lung volume, and compliance decrease [20]. Under VCV mode, a $38.6 \%$ increase and $37.5 \%$ increase of PAP were found, compared with the initial level, at $1 \mathrm{~min}$ and $10 \mathrm{~min}$, respectively, after suctions. We also found a $17.2 \%$ and $17.6 \%$ increase of $P_{\text {plat }}$ and a $32.5 \%$ and $31.7 \%$ decrease of $C_{\mathrm{rs}}$ at $1 \mathrm{~min}$ and $10 \mathrm{~min}$, respectively, after suctions under VCV mode. Given that $V_{T}$ under VCV mode was not changed, alveolar collapse would lead airway pressure to increase accordingly and overexpansion of the open alveolar may also cause increase in $P_{\text {plat }}$.

During mechanical ventilation, the retention of airway mucus causes increased airway resistance, which is manifested as increased airway pressure [21]. However, we found no significant airway pressure decrease after suctioning under VCV mode. The possible explanation could be that, in general, the insertion depth of the suction tube could only explore carina and bronchus to effectively remove the mucus of the proximal airway, while the leading factors that influence airway resistance are the small bronchi rather than the carina and bronchus. Due to the bronchial spasms resulting from stimulation of suction tube, along with other factors such as alveolar collapse and atelectasis, airway resistance after suction was not lower than the original level, which was presented as an increased $P_{\text {peak }}$ under VCV mode and a decreased $V_{T}$ under PCV mode. In addition, our results also suggested that the initial $\mathrm{PaO}_{2}$ increased by $6.4 \%$ and $10.2 \%$ at $3 \mathrm{~min}$ and $10 \mathrm{~min}$, respectively, after suctions under PCV mode, while $18.9 \%$ increase and $30.6 \%$ increase of the initial $\mathrm{PaO}_{2}$ were observed under VCV mode. There was a significant difference in the increment of the initial $\mathrm{PaO}_{2}$ between PCV and VCV modes. Our results are consistent with multiple previous studies [22-25].

In conclusion, our study provides a comprehensive and reliable evidence that endotracheal suctioning of ARF patients receiving mechanical ventilation may impair gas exchange and decrease lung compliance, under both PCV and VCV modes, but the effects of endotracheal suctioning on gas exchange were more severe and longer-lasting under PCV mode, in comparison to VCV mode.

\section{Conflict of Interests}

The authors have declared that they have no conflict of interests.

\section{Acknowledgments}

This study received the fund of Science Foundation of Science and Technology Bureau of Liaoning Province of China (no. 2008785). The authors would also like to thank all of their colleagues working in the Department of Emergency, the First Affiliated Hospital of China Medical University.

\section{References}

[1] S. Nava and N. Hill, "Non-invasive ventilation in acute respiratory failure," The Lancet, vol. 374, no. 9685, pp. 250-259, 2009.

[2] S. Nava, M. Grassi, F. Fanfulla et al., "Non-invasive ventilation in elderly patients with acute hypercapnic respiratory failure: a randomised controlled trial," Age and Ageing, vol. 40, no. 4, Article ID afr003, pp. 444-450, 2011.

[3] L. Vignaux, F. Vargas, J. Roeseler et al., "Patient-ventilator asynchrony during non-invasive ventilation for acute respiratory failure: a multicenter study," Intensive Care Medicine, vol. 35, no. 5, pp. 840-846, 2009.

[4] J. V. Diaz, R. Brower, C. S. Calfee, and M. A. Matthay, "Therapeutic strategies for severe acute lung injury," Critical Care Medicine, vol. 38, no. 8, pp. 1644-1650, 2010.

[5] S. Sud, J. O. Friedrich, P. Taccone et al., "Prone ventilation reduces mortality in patients with acute respiratory failure and severe hypoxemia: Systematic review and meta-analysis," Intensive Care Medicine, vol. 36, no. 4, pp. 585-599, 2010.

[6] S. Jaber, P. Michelet, and G. Chanques, "Role of non-invasive ventilation (NIV) in the perioperative period," Best Practice and Research: Clinical Anaesthesiology, vol. 24, no. 2, pp. 253-265, 2010.

[7] M. B. Domico, D. A. Ridout, R. Bronicki et al., "The impact of mechanical ventilation time before initiation of extracorporeal life support on survival in pediatric respiratory failure: a review of the extracorporeal life support registry," Pediatric Critical Care Medicine, vol. 13, no. 1, pp. 16-21, 2012.

[8] E. Kilger, P. Möhnle, K. Nassau et al., "Noninvasive mechanical ventilation in patients with acute respiratory failure after cardiac surgery," Heart Surgery Forum, vol. 13, no. 2, pp. E91-E95, 2010. 
[9] R. M. Kravitz, "Airway clearance in Duchenne muscular dystrophy," Pediatrics, vol. 123, supplement 4, pp. S231-S235, 2009.

[10] M. Antonelli, E. Azoulay, M. Bonten et al., "Year in review in Intensive Care Medicine 2009. Part III: mechanical ventilation, acute lung injury and respiratory distress syndrome, pediatrics, ethics, and miscellanea," Intensive Care Medicine, vol. 36, no. 4, pp. 567-584, 2010.

[11] S. Lasocki, Q. Lu, A. Sartorius, D. Fouillat, F. Remerand, and J. J. Rouby, "Open and closed-circuit endotracheal suctioning in acute lung injury: Efficiency and effects on gas exchange," Anesthesiology, vol. 104, no. 1, pp. 39-47, 2006.

[12] E. Belcher, M. Dusmet, S. Jordan, G. Ladas, E. Lim, and P. Goldstraw, "A prospective, randomized trial comparing BioGlue and Vivostat for the control of alveolar air leak," Journal of Thoracic and Cardiovascular Surgery, vol. 140, no. 1, pp. 32-38, 2010.

[13] L. Cabrini, G. Landoni, and A. Zangrillo, "Noninvasive ventilation failure: the answer is blowing in the leaks," Respiratory Care, vol. 56, no. 11, pp. 1857-1858, 2011.

[14] M. Al-Hegelan and N. R. Macintyre, "Novel modes of mechanical ventilation," Seminars in Respiratory and Critical Care Medicine, vol. 34, no. 4, pp. 499-507, 2013.

[15] O. Stenqvist, S. Lindgren, S. Kárason, S. Söndergaard, and S. Lundin, "Warning! Suctioning. A lung model evaluation of closed suctioning systems," Acta Anaesthesiologica Scandinavica, vol. 45, no. 2, pp. 167-172, 2001.

[16] I. P. Jongerden, M. M. Rovers, M. H. Grypdonck, and M. J. Bonten, "Open and closed endotracheal suction systems in mechanically ventilated intensive care patients: a metaanalysis," Critical Care Medicine, vol. 35, no. 1, pp. 260-270, 2007.

[17] L. Valizadeh, R. Janani, L. Janani, and F. Galechi, "Neonatal intensive care units nurses' attitude toward advantages and disadvantages of open vs closed endotracheal suction," Nursing and Midwifery Studies, vol. 3, no. 2, 2014.

[18] R. S. Campbell and B. R. Davis, "Pressure-controlled versus volume-controlled ventilation: does it matter?" Respiratory Care, vol. 47, no. 4, pp. 416-424, 2002.

[19] L. Brochard, F. Roudot-Thoraval, E. Roupie et al., "Tidal volume reduction for prevention of ventilator-induced lung injury in acute respiratory distress syndrome. The Multicenter Trail Group on Tidal Volume reduction in ARDS," American Journal of Respiratory and Critical Care Medicine, vol. 158, no. 6, pp. 1831-1838, 1998.

[20] J. S.-P. Choi and A. Y.-M. Jones, "Effects of manual hyperinflation and suctioning on respiratory mechanics in mechanically ventilated patients with ventilator-associated pneumonia," Australian Journal of Physiotherapy, vol. 51, no. 1, pp. 25-30, 2005.

[21] S. T. Larsen, P. Wolkoff, M. Hammer, V. Kofoed-Sørensen, P. A. Clausen, and G. D. Nielsen, "Acute airway effects of airborne formaldehyde in sensitized and non-sensitized mice housed in a dry or humid environment," Toxicology and Applied Pharmacology, vol. 268, no. 3, pp. 294-299, 2013.

[22] B. Almgren, C.-J. Wickerts, E. Heinonen, and M. Högman, "Side effects of endotracheal suction in pressure- and volumecontrolled ventilation," Chest, vol. 125, no. 3, pp. 1077-1080, 2004.

[23] M. Cereda, F. Villa, E. Colombo, G. Greco, M. Nacoti, and A. Pesenti, "Closed system endotracheal suctioning maintains lung volume during volume-controlled mechanical ventilation," Intensive Care Medicine, vol. 27, no. 4, pp. 648-654, 2001.

[24] S. M. Maggiore, E. Iacobone, G. Zito, C. Conti, M. Antonelli, and R. Proietti, "Closed versus open suctioning techniques," Minerva Anestesiologica, vol. 68, no. 5, pp. 360-364, 2002.
[25] M. Tuğrul, E. Çamci, H. Karadeniz, M. Şentürk, K. Pembeci, and K. Akpir, "Comparison of volume controlled with pressure controlled ventilation during one-lung anaesthesia," British Journal of Anaesthesia, vol. 79, no. 3, pp. 306-310, 1997. 


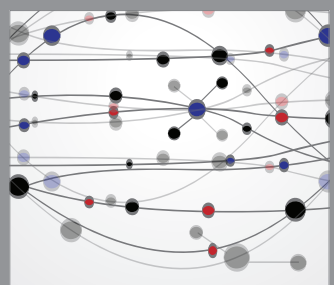

The Scientific World Journal
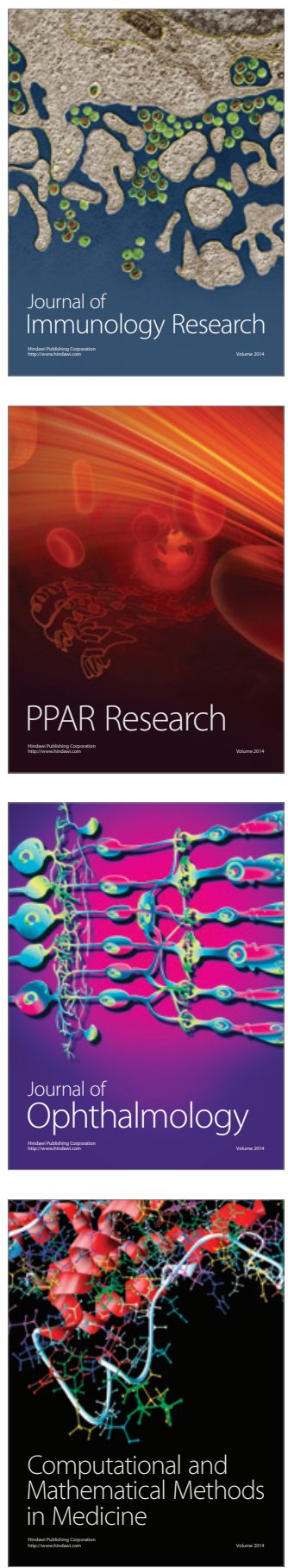

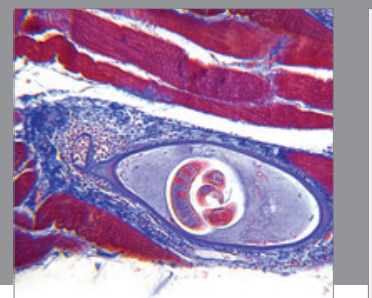

Gastroenterology

Research and Practice
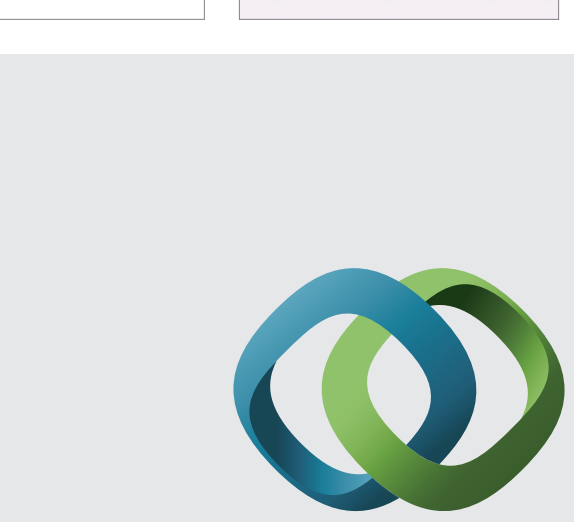

\section{Hindawi}

Submit your manuscripts at

http://www.hindawi.com
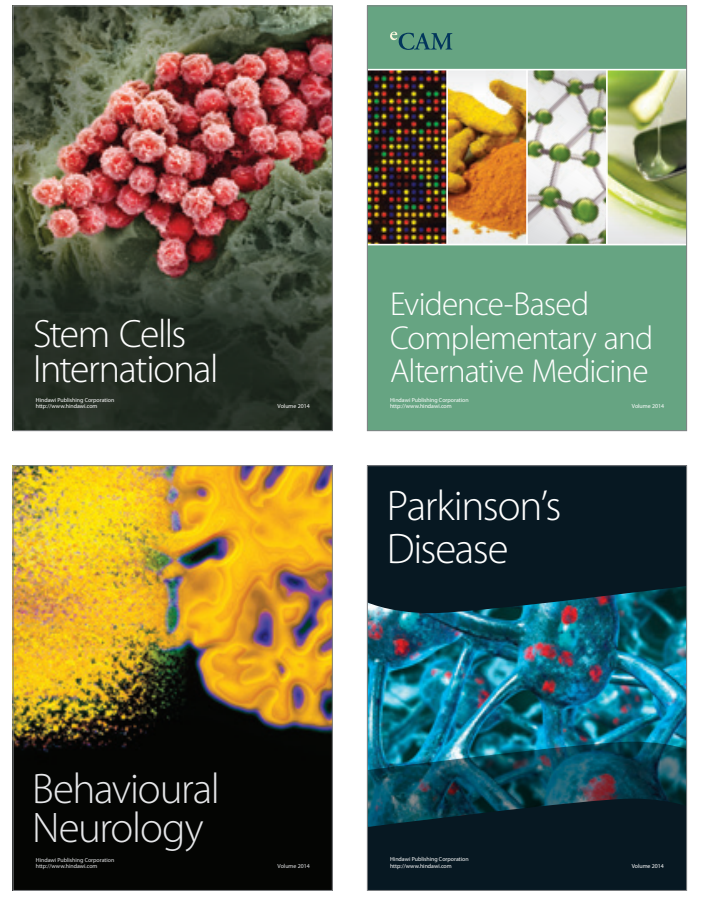
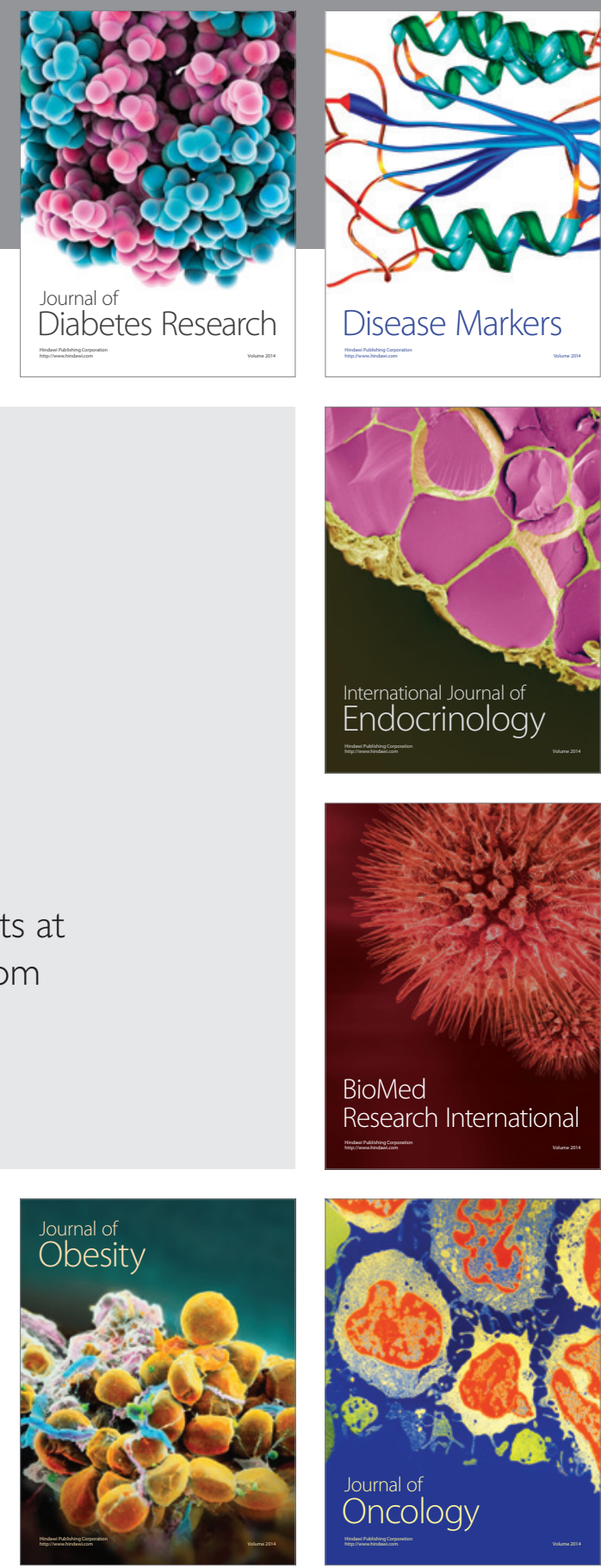

Disease Markers
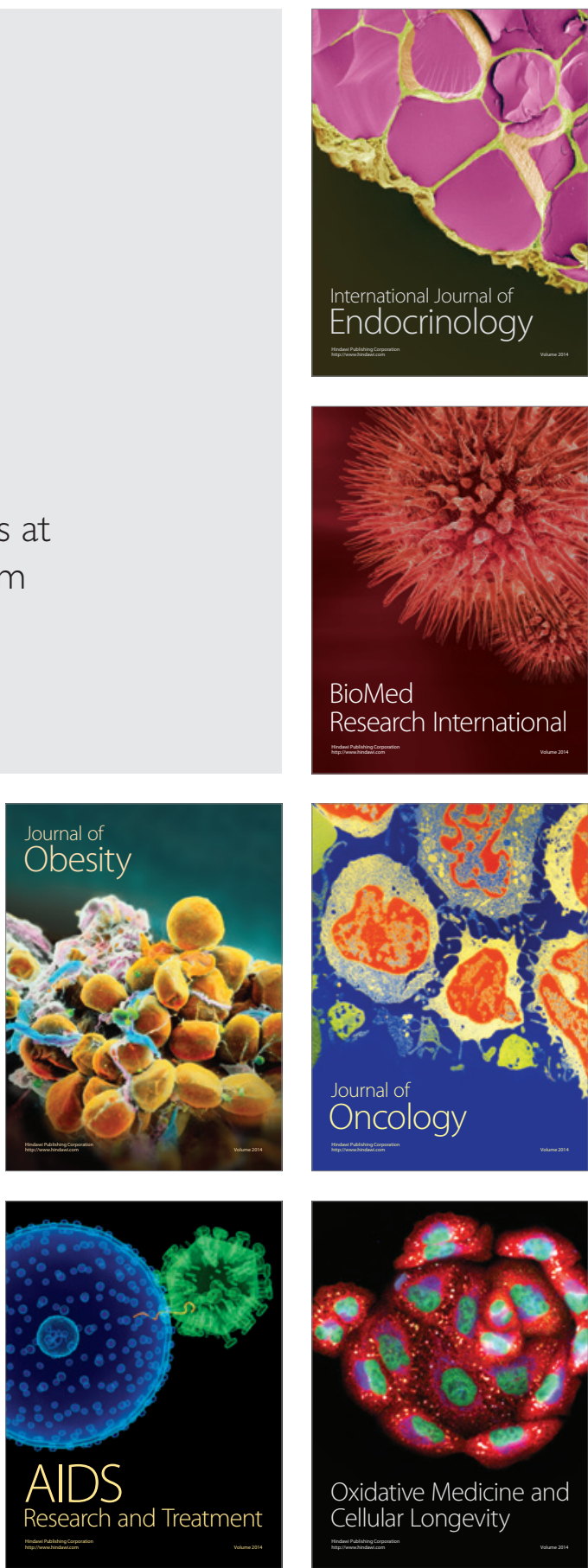